\title{
A Meir-Keeler common type fixed point theorem on partial metric spaces
}

Hassen Aydi $i^{*}$ and Erdal Karapinar ${ }^{2}$

* Correspondence: hassen. aydi@isima.rnu.tn

${ }^{1}$ Institut Supérieur d'Informatique et des Technologies de Communication de Hammam Sousse, Université de Sousse, Route GP1-4011, Hammam Sousse, Tunisie

Full list of author information is available at the end of the article

\section{Abstract}

In this article, we prove a general common fixed point theorem for two pairs of weakly compatible self-mappings of a partial metric space satisfying a generalized Meir-Keeler type contractive condition. The presented theorem extends several well known results in literature.

\section{Introduction}

Partial metric spaces were introduced by Matthews [1] to study denotational semantics of dataflow networks. In fact, (complete) partial metric spaces constitute a suitable framework to model several distinguished examples of the theory of computation and also to model metric spaces via domain theory. For example, in the research area of computer domains and semantics, partial metric spaces have serious applications potentials (see for example, [2-5]). In 1994, Matthews [1] generalized the Banach contraction principle to the class of complete partial metric spaces: a self mapping $T$ on a complete partial metric space $(X, p)$ has a unique fixed point if there exists $0 \leq k<1$ such that $p(T x, T y) \leq k p(x, y)$ for all $x, y \in X$. After the remarkable contribution of Matthews, many authors have studied on partial metric spaces and its topological properties (see for example, [1-28]).

In the sequel we recall the notion of a partial metric space and some of its properties which will be useful later on. A partial metric is a function $p: X \times X \rightarrow[0, \infty)$ satisfying the following conditions

(P1) $p(x, y)=p(y, x)$,

(P2) If $p(x, x)=p(x, y)=p(y, y)$, then $x=y$,

(P3) $p(x, x) \leq p(x, y)$,

(P4) $p(x, z)+p(y, y) \leq p(x, y)+p(y, z)$,

for all $x, y, z \in X$. Then $(X, p)$ is called a partial metric space. If $p$ is a partial metric $p$ on $X$, then the function $d_{p}: X \times X \rightarrow[0, \infty)$ given by

$$
d_{p}(x, y)=2 p(x, y)-p(x, x)-p(y, y)
$$

is a metric on $X$. Also, each partial metric $p$ on $X$ generates a $T_{0}$ topology $\tau_{p}$ on $X$ with a base of the family of open $p$-balls $\left\{B_{p}(x, \varepsilon): x \in X, \varepsilon>0\right\}$, where $B_{p}(x, \varepsilon)=\{y \in$ $X: p(x, y)<p(x, x)+\varepsilon\}$ for all $x \in X$ and $\varepsilon>0$. Similarly, closed $p$-ball is defined as $B_{p}$ $[x, \varepsilon]=\{y \in X: p(x, y) \leq p(x, x)+\varepsilon\}$.

(c) 2012 Aydi and Karapinar; licensee Springer. This is an Open Access article distributed under the terms of the Creative Commons Attribution License (http://creativecommons.org/licenses/by/2.0), which permits unrestricted use, distribution, and reproduction in any medium, provided the original work is properly cited. 
Definition 1.1. $[1,7]$ Let $(X, p)$ be a partial metric space.

(i) A sequence $\left\{x_{n}\right\}$ in $X$ converges to $x \in X$ whenever $\lim _{n \rightarrow \infty} p\left(x, x_{n}\right)=p(x, x)$,

(ii) A sequence $\left\{x_{n}\right\}$ in $X$ is called Cauchy whenever $\lim _{n, m \rightarrow \infty} p\left(x_{n}, x_{m}\right)$ exists (and finite),

(iii) $(X, p)$ is said to be complete if every Cauchy sequence $\left\{x_{n}\right\}$ in $X$ converges, with respect to $\tau_{p}$, to a point $x \in X$, that is, $\lim _{n, m \rightarrow \infty} p\left(x_{n}, x_{m}\right)=p(x, x)$.

(iv) A mapping $f: X \rightarrow X$ is said to be continuous at $x_{0} \in X$ if for each $\varepsilon>0$ there exists $\delta>0$ such that $f\left(B\left(x_{0}, \delta\right)\right) \subset B\left(f\left(x_{0}\right), \varepsilon\right)$.

Lemma 1.1. $[1,7]$ Let $(X, p)$ be a partial metric space.

(a) A sequence $\left\{x_{n}\right\}$ is Cauchy if and only if $\left\{x_{n}\right\}$ is a Cauchy sequence in the metric space $\left(X, d_{p}\right)$,

(b) $(X, p)$ is complete if and only if the metric space $\left(X, d_{p}\right)$ is complete. Moreover,

$$
\lim _{n \rightarrow \infty} d_{p}\left(x, x_{n}\right)=0 \Leftrightarrow \lim _{n \rightarrow \infty} p\left(x, x_{n}\right)=\lim _{n, m \rightarrow \infty} p\left(x_{n}, x_{m}\right)=p(x, x) .
$$

Definition 1.2. [29] Let $X$ be a non empty set and $f, g: X \rightarrow X$. If $w=f x=g x$, for some $x \in X$, then $x$ is called a coincidence point of $f$ and $g$, and $w$ is called a point of coincidence of $f$ and $g$. If $w=x$, then $x$ is a common fixed point of $f$ and $g$.

Definition 1.3. [29]Let $f$ and $g$ be two self-maps defined on a non empty set $X$. Then $f$ and $g$ are said to be weakly compatible if they commute at every coincidence point.

Recently, Ćirić et al. [17] established a common fixed point result for two pairs of weakly compatible mappings satisfying generalized contractions on a partial metric space. For this, denote by $\Phi$ the set of non-decreasing continuous functions $\phi: \mathbb{R} \rightarrow \mathbb{R}$ satisfying:

(a) $0<\phi(t)<t$ for all $t>0$,

(b) the series $\sum_{\mathrm{n} \geq 1} \phi^{n}(t)$ converge for all $t>0$.

The result [17] is the following.

Theorem 1.2. Suppose that $A, B, S$, andT are self-maps of a complete partial metric space $(X, p)$ such that $A X \subseteq T X, B X \subseteq S X$ and

$$
p(A x, B y) \leq \varphi(M(x, y))
$$

for all $x, y \in X$, where $\phi \in \Phi$ and

$$
M(x, y)=\max \left\{p(S x, T y), p(A x, S x), p(B y, T y), \frac{1}{2}[p(S x, B y)+p(A x, T y)]\right\} .
$$

If one of the ranges $A X, B X, T X$ and $S X$ is a closed subset of $(X, p)$, then

(i) $A$ and $S$ have a coincidence point,

(ii) $B$ and $T$ have a coincidence point.

Moreover, if the pairs $\{A, S\}$ and $\{B, T\}$ are weakly compatible, then $A, B, T$, and $S$ have a unique common fixed point.

In this manuscript, replacing (2) by some new weaker hypotheses we also establish a common fixed point result for four self maps satisfying a generalized Meir-Keeler type contraction on partial metric spaces. Our theorem generalizes several well known results in the literature. 


\section{Main results}

The following lemmas will be frequently used in the proofs of the main results.

Lemma 2.1. $[6,19]$ Let $(X, p)$ be a partial metric space. Then

(a) If $p(x, y)=0$, then $x=y$,

(b) If $x \neq y$, then $p(x, y)>0$.

Lemma 2.2. $[6,19]$ Let $(X, p)$ be a partial metric space and $x_{n} \rightarrow z$ with $p(z, z)=0$. Then $\lim _{n \rightarrow \infty} p\left(x_{n}, y\right)=p(z, y)$ for all $y \in X$.

Now, we are ready to state and prove our main result.

Theorem 2.3. Let $A, B, S$, and $T$ be the self maps defined on a complete partial metric space $(X, p)$ satisfying the following conditions:

(C1) $A X \subseteq T X$ and $B X \subseteq S X$,

(C2) for all $\varepsilon>0$, there exists $\delta>0$ such that for all $x, y \in X$

$$
\varepsilon<M(x, y)<\varepsilon+\delta \Rightarrow p(A x, B y) \leq \varepsilon,
$$

where $M(x, y)=\max \left\{p(S x, T y), p(A x, S x), p(B y, T y), \frac{1}{2}[p(S x, B y)+p(A x, T y)]\right\}$,

(C3) for all $x, y \in X$ with $M(x, y)>0 \Rightarrow p(A x, B y)<M(x, y)$,

(C4) $p(A x, B y) \leq \max \{a[p(S x, T y)+p(A x, S x)+p(B y, T y)], b[p(S x, B y)+p(A x, T y]\}$ for all $x, y \in X, 0 \leq a<\frac{1}{2}$ and $0 \leq b<\frac{1}{2}$.

If one of the ranges $A X, B X, T X$, and $S X$ is a closed subset of $(X, p)$, then

(I) $A$ and $S$ have a coincidence point,

(II) $B$ and $T$ have a coincidence point.

Moreover, if $A$ and $S$, as well as, $B$ and $T$ are weakly compatible, then $A, B, S$, and $T$ have a unique common fixed point.

Proof. Let $x_{0}$ be an arbitrary point in $X$. Since $A X \subseteq T X$, there exists $x_{1} \in X$ such that $T x_{1}=A x_{0}$. Since $B X \subseteq S X$, there exists $x_{2} \in X$ such that $S x_{2}=B x_{1}$. Continuing this process, we can construct sequences $\left\{x_{n}\right\}$ and $\left\{y_{n}\right\}$ in $X$ defined by

$$
y_{2 n}=T x_{2 n+1}=A x_{2 n}, \quad y_{2 n+1}=S x_{2 n+2}=B x_{2 n+1} \quad \forall n \in \mathbb{N} .
$$

Suppose $p\left(y_{2 n}, y_{2 n+1}\right)=0$ for some $n$. Then $y_{2 n}=\mathrm{y}_{2 n+1}$ implies that $A x_{2 n}=T x_{2 n+1}=$ $B x_{2 n+1}=S x_{2 n+2}$, so $T$ and $B$ have a coincidence point. Further, if $p\left(y_{2 n+1}, y_{2 n+2}\right)=0$ for some $n$ then $A x_{2 n+2}=T x_{2 n+3}=B x_{2 n+1}=S x_{2 n+2}$, so $A$ and $S$ have a coincidence point. For the rest, assume that $p\left(y_{n}, y_{n+1}\right) \neq 0$ for all $n \geq 0$.

If for some $x, y \in X, M(x, y)=0$, then we get that $A x=S x$ and $B y=T y$, so we proved (I) and (II).

If $M(x, y)>0$ for all $x, y \in X$, then by (C3),

$$
p(A x, B y)<M(x, y) \text { for all, } x, y \in X .
$$

Hence, we have

$$
\begin{aligned}
& p\left(y_{2 p}, y_{2 p+1}\right)<M\left(x_{2 p}, x_{2 p+1}\right)= \\
& \max \left\{p\left(S x_{2 p}, T x_{2 p+1}\right), p\left(A x_{2 p}, S x_{2 p}\right), p\left(B x_{2 p+1}, T x_{2 p+1}\right), \frac{1}{2}\left[p\left(S x_{2 p}, B x_{2 p+1}\right)+p\left(A x_{2 p}, T x_{2 p+1}\right)\right]\right\} \\
& =\max \left\{p\left(\gamma_{2 p-1}, \gamma_{2 p}\right), p\left(\gamma_{2 p}, \gamma_{2 p-1}\right), p\left(\gamma_{2 p+1}, \gamma_{2 p}\right), \frac{1}{2}\left[p\left(\gamma_{2 p-1}, \gamma_{2 p+1}\right)+p\left(\gamma_{2 p}, \gamma_{2 p}\right)\right]\right\} \\
& \leq \max \left\{p\left(\gamma_{2 p-1}, \gamma_{2 p}\right), p\left(\gamma_{2 p+1}, \gamma_{2 p}\right), \frac{1}{2}\left[p\left(\gamma_{2 p-1}, \gamma_{2 p}\right)+p\left(\gamma_{2 p}, \gamma_{2 p+1}\right)\right]\right\} \\
& =\max \left\{p\left(\gamma_{2 p-1}, \gamma_{2 p}\right), p\left(\gamma_{2 p}, \gamma_{2 p+1}\right)\right\}
\end{aligned}
$$


since

$$
p\left(\gamma_{2 p-1}, \gamma_{2 p+1}\right)+p\left(\gamma_{2 p}, \gamma_{2 p}\right) \leq p\left(\gamma_{2 p-1}, \gamma_{2 p}\right)+p\left(\gamma_{2 p}, \gamma_{2 p+1}\right)
$$

It is easy that $\max \left\{p\left(y_{2 p-1}, y_{2 p}\right), p\left(y_{2 p}, y_{2 p+1}\right)\right\}=p\left(y_{2 p}, y_{2 p+1}\right)$ is excluded. It follows that

$$
p\left(y_{2 p}, y_{2 p+1}\right)<M\left(x_{2 p}, x_{2 p+1}\right) \leq p\left(y_{2 p-1}, y_{2 p}\right) \quad \text { for all } p \geq 1
$$

Similarly, one can find

$$
p\left(y_{2 p+2}, y_{2 p+1}\right)<M\left(x_{2 p+2} x_{2 p+1}\right) \leq p\left(y_{2 p+1}, y_{2 p}\right) \quad \text { for all } p \geq 0 \text {. }
$$

We deduce that

$$
p\left(y_{n}, y_{n+1}\right)<p\left(y_{n-1}, y_{n}\right) \text { for all } n \geq 1 \text {. }
$$

Thus, $\left\{p\left(y_{n}, y_{n+1}\right)\right\}_{n=0}^{\infty}$ is a decreasing sequence which is bounded below by 0 . Hence, it converges to some $L \in[0, \infty)$, that is,

$$
\lim _{n \rightarrow \infty} p\left(y_{n}, y_{n+1}\right)=L \text {. }
$$

We claim that $L=0$. If $L>0$, then from (8), there exist $\delta>0$ and a natural number $m \geq 1$ such that for each $n \geq m L<d\left(y_{n}, y_{n+1}\right)<L+\delta$. In particular, from this and (6)

$$
L<M\left(x_{2 m}, x_{2 m+1}\right)<L+\delta .
$$

Now by using (3), we get that $p\left(A x_{2 m}, B x_{2 m+1}\right)=p\left(y_{2 m}, y_{2 m+1}\right) \leq L$ which is a contradiction. Thus, $L=0$, that is,

$$
\lim _{n \rightarrow \infty} p\left(y_{n}, y_{n+1}\right)=0 \text {. }
$$

We claim that $\left\{y_{n}\right\}$ is a Cauchy sequence in the partial metric space $(X, p)$. From Lemma 1.1, we need to prove that $\left\{y_{n}\right\}$ is Cauchy in the metric space $\left(\mathrm{X}, d_{p}\right)$. We argue by contradiction. Then there exist $\varepsilon>0$ and a subsequence $\left\{y_{n(i)}\right\}$ of $\left\{y_{n}\right\}$ such that $d_{p}\left(y_{n(i)}, y_{n(i+1)}\right)>4 \varepsilon$. Select $\delta$ in $(\mathrm{C} 2)$ as $0<\delta \leq \varepsilon$. By definition of the metric $d_{p}$,

$$
d_{p}(x, y) \leq 2 p(x, y) \quad \text { for all } x, y \in X,
$$

so $p\left(y_{n(i)}, y_{n(i+1)}\right)>2 \varepsilon$. Since $\lim _{n \rightarrow \infty} p\left(y_{n}, y_{n+1}\right)=0$, hence there exists $N \in \mathbb{N}$ such that

$$
p\left(y_{n}, y_{n+1}\right)<\frac{\delta}{6} \quad \text { whenever } n \geq N \text {. }
$$

Let $n(i) \geq N$. Then, there exist integers $m(i)$ satisfying $n(i)<m(i)<n(i+1)$ such that

$$
p\left(y_{n(i)}, y_{m(i)}\right) \geq \varepsilon+\frac{\delta}{3} \text {. }
$$

If not, then by triangle inequality (which holds even for partial metrics)

$$
\begin{aligned}
p\left(y_{n(i)}, y_{n(i+1)}\right) & \leq p\left(y_{n(i)}, y_{n(i+1)-1}\right)+p\left(y_{n(i+1)-1}, y_{n(i+1)}\right) \\
& <\varepsilon+\frac{\delta}{3}+\frac{\delta}{6}<2 \varepsilon
\end{aligned}
$$

it is a contradiction. Without loss of generality, we can assume $n(i)$ to be odd. Let $m$ (i) be the smallest even integer such that 


$$
p\left(y_{n(i)}, y_{m(i)}\right) \geq \varepsilon+\frac{\delta}{3}
$$

Then

$$
p\left(y_{n(i)}, y_{m(i)-2}\right)<\varepsilon+\frac{\delta}{3}
$$

and

$$
\begin{aligned}
\varepsilon+\frac{\delta}{3} & \leq p\left(\gamma_{n(i)}, \gamma_{m(i)}\right) \leq p\left(\gamma_{n(i)}, \gamma_{m(i)-2}\right)+p\left(\gamma_{m(i)-2}, \gamma_{m(i)-1}\right)+p\left(\gamma_{m(i)-1}, \gamma_{m(i)}\right) \\
& <\varepsilon+\frac{\delta}{3}+\frac{\delta}{6}+\frac{\delta}{6}=\varepsilon+2 \frac{\delta}{3} .
\end{aligned}
$$

Also, $p\left(y_{n(i)}, y_{m(i)}\right) \leq M\left(x_{n(i)+1}, x_{m(i)+1}\right)<\varepsilon+2 \frac{\delta}{3}+\frac{\delta}{6}<\varepsilon+\delta$, that is,

$$
\varepsilon<\varepsilon+\frac{\delta}{3} \leq M\left(x_{n(i)+1}, x_{m(i)+1}\right)<\varepsilon+\delta .
$$

In view of $(\mathrm{C} 2)$, this yields that $p\left(y_{n(i)+1}, y_{m(i)+1}\right) \leq \varepsilon$. But then

$$
\begin{aligned}
p\left(y_{n(i)}, y_{m(i)}\right) & \leq p\left(y_{n(i)}, y_{n(i)+1}\right)+p\left(y_{n(i)+1}, y_{m(i)+1}\right)+p\left(y_{m(i)+1}, y_{m(i)}\right) \\
& <\frac{\delta}{6}+\varepsilon+\frac{\delta}{6}=\varepsilon+\frac{\delta}{3},
\end{aligned}
$$

which contradicts (10). Hence $\left\{y_{n}\right\}$ is a Cauchy sequence in the metric space $\left(X, d_{p}\right)$, so also in the partial metric $(X, p)$ which is complete. Thus, there exists a point $y$ in $X$ such that from Lemmas 1.1, 2.2, and (9)

$$
p(y, y)=\lim _{n \rightarrow \infty} p\left(y_{n}, y\right)=\lim _{n \rightarrow \infty} p\left(y_{n}, y_{n}\right)=0 .
$$

This implies that

$$
\lim _{n \rightarrow+\infty} p\left(\gamma_{2 n}, y\right)=\lim _{n \rightarrow+\infty} p\left(y_{2 n-1}, y\right)=0 .
$$

Thus from (13) we have

$$
\lim _{n \rightarrow+\infty} p\left(A x_{2 n}, y\right)=\lim _{n \rightarrow+\infty} p\left(T x_{2 n+1}, y\right)=0
$$

and

$$
\lim _{n \rightarrow+\infty} p\left(B x_{2 n-1}, y\right)=\lim _{n \rightarrow+\infty} p\left(S x_{2 n}, y\right)=0 .
$$

Now we can suppose, without loss of generality, that $S X$ is a closed subset of the partial metric space $(X, p)$. From (15), there exists $u \in X$ such that $y=S u$. We claim that $p(A u, y)=0$. Suppose, to the contrary, that $p(A u, y)>0$.

By (P4) and (C4) we get

$$
\begin{aligned}
& p(y, A u) \leq p\left(y, B x_{2 n+1}\right)+p\left(A u, B x_{2 n+1}\right)-p\left(B x_{2 n+1}, B x_{2 n+1}\right) \\
& \leq p\left(y, B x_{2 n+1}\right)+p\left(A u, B x_{2 n+1}\right) \\
& \leq p\left(y, B x_{2 n+1}\right)+\max \left\{a\left[p\left(\gamma, y_{2 n}\right)+p(A u, y)+p\left(y_{2 n+1}, y_{2 n}\right)\right]\right. \text { ， } \\
& \left.b\left[p\left(y, \gamma_{2 n+1}\right)+p\left(A u, \gamma_{2 n}\right)\right]\right\} \\
& \leq p\left(\gamma, B x_{2 n+1}\right)+\max \left\{a\left[p\left(\gamma, \gamma_{2 n}\right)+p(A u, \gamma)+p\left(\gamma_{2 n+1}, \gamma_{2 n}\right)\right]\right. \text {, } \\
& \left.b\left[p\left(y, y_{2 n+1}\right)+p(A u, y)+p\left(y, y_{2 n}\right)-p(y, y)\right]\right\} .
\end{aligned}
$$


Letting $n \rightarrow \infty$ in the above inequality and using (12)-(15), we obtain

$$
0<p(y, A u) \leq \max \{a p(A u, y), b p(A u, y)\}<p(A u, y)
$$

it is a contradiction since $0 \leq a<\frac{1}{2}<1$ and $0 \leq b<\frac{1}{2}<1$. Thus, by Lemma 2.1, we deduce that

$$
p(A u, y)=0 \text { and } y=A u .
$$

Since $y=S u$, then $A u=S u$, that is, $u$ is a coincidence point of $A$ and $S$. So we proved (I).

From $A X \subseteq T X$ and (16), we have $y \in T X$. Hence we deduce that there exists $v \in X$ such that $y=T v$. We claim that $p(B v, y)=0$. Suppose, to the contrary, that $p(B v, y)>$ 0 . From (C4) and (16), we have

$$
\begin{aligned}
0<p(y, B v)=p(A u, B v) \leq & \max \{a[p(S u, T v)+p(A u, S u)+p(B v, T v)], \\
& b[p(S u, B v)+p(A u, T v)]\} \\
= & \max \{a[p(y, y)+p(y, y)+p(B v, y)] \\
& b[p(\gamma, B v)+p(\gamma, y)]\} \\
= & \max \{a p(B v, y), b p(B v, y)\}
\end{aligned}
$$

as $y=S u=A u=T v$ and $p(y, y)=0$. Since $0 \leq a<1$ and $0 \leq b<1$, this implies that

$$
p(B v, y)<p(B v, y)
$$

which is a contradiction. Then, we deduce that

$$
p(B v, y)=0 \text { and } y=B v=T v,
$$

that is, $v$ is a coincidence point of $B$ and $T$, then (II) holds.

Since the pair $\{A, S\}$ is weakly compatible, from (16), we have $A y=A S u=S A u=S y$. We claim that $p(A y, y)=0$. Suppose, to the contrary, that $p(A y, y)>0$. We have

$$
\begin{aligned}
p(A y, y) \leq & p\left(A y, y_{2 n+1}\right)+p\left(y_{2 n+1}, \gamma\right) \\
= & p\left(A y, B x_{2 n+1}\right)+p\left(y_{2 n+1}, \gamma\right) \\
\leq & p\left(y_{2 n+1}, \gamma\right)+\max \left\{a\left[p\left(S y, T x_{2 n+1}\right)+p(A y, S y)+p\left(B x_{2 n+1}, T x_{2 n+1}\right)\right],\right. \\
& \left.b\left[p\left(S y, B x_{2 n+1}\right)+p\left(A y, T x_{2 n+1}\right)\right]\right\} \\
= & p\left(y_{2 n+1}, y\right)+\max \left\{a\left[p\left(A y, y_{2 n}\right)+p(A y, A y)+p\left(y_{2 n+1}, y_{2 n}\right)\right],\right. \\
& \left.b\left[p\left(A y, y_{2 n+1}\right)+p\left(A y, y_{2 n}\right)\right]\right\} .
\end{aligned}
$$

Using (12) and (p2), we get letting $n \rightarrow+\infty$

$$
0<p(A y, y) \leq \max \{2 a p(A y, y), 2 b p(A y, y)\}<p(A y, y)
$$

a contradiction. Then we deduce that

$$
p(A y, y)=0 \text { and } A y=S y=\gamma \text {. }
$$

Since the pair $\{B, T\}$ is weakly compatible, from (17), we have $B y=B T v=T B v=T y$. We claim that $p(B y, y)=0$. Suppose, to the contrary, that $p(B y, y)>0$, then by $(C 4)$ and (18), we have 


$$
\begin{aligned}
0<p(y, B y)=p(A y, B y) \leq & \max \{a[p(S y, T y)+p(A y, S y)+p(B y, T y)] \\
& b[p(S y, B y)+p(A y, T y)]\} \\
= & \max \{a[p(y, B y)+p(y, y)+p(B y, B y)], b[p(y, B y)+p(y, B y)]\} \\
\leq & \max \{2 a, 2 b\} p(B y, y),
\end{aligned}
$$

since $p(y, y)=0$. Thus, we get

$$
p(y, B y)=0 \text { and } B y=T y=\gamma .
$$

Now, combining (18) and (19), we obtain

$$
y=A y=B y=S y=T y,
$$

that is, $y$ is a common fixed point of $A, B, S$, and $T$ with $p(y, y)=0$.

Now we prove the uniqueness of a common fixed point. Let us suppose that $z \in X$ is a common fixed point of $A, B, S$, and $T$ such that $p(z, y)>0$. Using (iv), we get

$$
\begin{aligned}
p(y, z) & =p(A y, B z) \\
& \leq \max \{a[p(A y, B z)+p(A y, A y)+p(B z, B z)], b[p(A y, B z)+p(A z, B y)]\} \\
& =\max \{a[p(y, z)+p(y, y)+p(z, z)], 2 b p(y, z)\} \\
& \leq \max \{2 a, 2 b\} p(y, z))<p(y, z),
\end{aligned}
$$

which is a contradiction. Then we deduce that $z=y$. Thus the uniqueness of the common fixed point is proved. The proof is completed.

Repeating the proof of Theorem 2.3, we get easily the following.

Corollary 2.4. Let $A, B, S$, and $T$ be the self maps defined on a partial metric space $(X, p)$ satisfying the following conditions:

(C1) $A X \subseteq T X$ and $B X \subseteq S X$,

(C2) for all $\varepsilon>0$, there exists $\delta>0$ such that for all $x, y \in X$

$$
\varepsilon<M(x, y)<\varepsilon+\delta \Rightarrow p(A x, B y) \leq \varepsilon,
$$

where $M(x, y)=\max \left\{p(S x, T y), p(A x, S x), p(B y, T y), \frac{1}{2}[p(S x, B y)+p(A x, T y)]\right\}$,

(C3) for all $x, y \in X$ with $M(x, y)>0 \Rightarrow p(A x, B y)<M(x, y)$,

(C4) $p(A x, B y)<k[p(S x, T y)+p(A x, S x)+p(B y, T y)+p(S x, B y)+p(A x, T y]$ for all $x$, $y \in X$ and $0 \leq k<\frac{1}{3}$.

If one of $A X, B X, S X$, or $T X$ is a complete subspace of $X$, then

(I) $A$ and $S$ have a coincidence point,

(II) $B$ and $T$ have a coincidence point.

Moreover, if $A$ and $S$, as well as, $B$ and $T$ are weakly compatible, then $A, B, S$, and $T$ have a unique common fixed point.

\section{Some equivalence statements of Meir-Keeler contraction}

Jachymski [30] proved the following important lemma.

Lemma 3.1. Let $\mathbb{Q}$ be a subset of $[0, \infty) \times[0, \infty)$. Then the following statements are equivalent:

(J1) There exists a function $\delta:(0, \infty) \rightarrow(0, \infty)$ such that for any $\varepsilon>0, \delta(\varepsilon)>\varepsilon$ and

$(J 1 a) \sup \{\delta(s): s \in(0, \varepsilon)\} \geq \delta(\varepsilon)$ and

$(J 1 b)(s, t) \in \mathbb{Q}$ and $0 \leq s<\delta(\varepsilon)$ imply $t<\varepsilon$. 
(J2) There exist functions $\beta, \eta:(0, \infty) \rightarrow(0, \infty)$ such that, for any $\varepsilon>0, \beta(\varepsilon)>\varepsilon, \eta(\varepsilon)$ $<\varepsilon$, and $(s, t) \in \mathbb{Q}$ and $0 \leq s<\beta(\varepsilon)$ imply $t<\eta(\varepsilon)$.

(J3) There exists an upper semi continuous function $\varphi:[0, \infty) \rightarrow[0, \infty)$ such that $\varphi$ is non-decreasing, $\varphi(s)<s$ for $s>0$, and $(s, t) \in \mathbb{Q}$ implies $t \leq \varphi(s)$.

(J4) There exists a lower-semi continuous function $\delta:(0, \infty) \rightarrow(0, \infty)$ such that for any $\delta$ is non-decreasing, for any $\varepsilon>0, \delta(\varepsilon)>\varepsilon$, and $(s, t) \in \mathbb{Q}$ and $0 \leq s<\delta(\varepsilon)$ imply $t<\varepsilon$.

(J5) There exists a lower-semi continuous function $\omega:[0, \infty) \rightarrow[0, \infty)$ such that for any $\omega$ is non-decreasing, $\omega(s)>s$ for $s>0$ and $(s, t) \in \mathbb{Q}$ implies $w(t) \leq s$.

Theorem 3.2. Let $(X, p)$ be a partial metric space, and $S, T, A_{i}(i \in \mathbb{N})$ be self-mappings on $X$. For $x, y \in X$ and for $i, j \in \mathbb{N}$, we define

$$
M_{i j}(x, y)=\left\{p(S x, T y), p\left(S x, A_{i} x\right), p\left(T y, A_{j} y\right), \frac{\left[p\left(S x, A_{j} y\right)+p\left(T y, A_{i} x\right)\right]}{2}\right\} .
$$

Then the following statements are equivalent.

(JT1) There exists a lower-semi continuous function $\delta:(0, \infty) \rightarrow(0, \infty)$ such that, for any $\varepsilon>0, \delta(\varepsilon)>\varepsilon$ and for any $x, y \in X$ and distinct $i, j \in \mathbb{N}$

$$
\varepsilon \leq M_{i j}(x, y)<\delta(\varepsilon) \text { implies } p\left(A_{i} x, A_{j} y\right)<\varepsilon .
$$

(JT2) There exists an upper-semi continuous function $\varphi:[0, \infty) \rightarrow[0, \infty)$ such that, $\varphi$ is non-decreasing, $\varphi(t)<t$, and

$$
p\left(A_{i} x, A_{j} y\right) \leq \phi\left(M_{i j}(x, y)\right) .
$$

for any $x, y \in X$ and distinct $i, j \in \mathbb{N}$.

(JT3) There exists a lower-semi continuous function $\omega:[0, \infty) \rightarrow[0, \infty)$ such that, $\omega$ is non-decreasing, $\omega(s)>s$ for $s>0$, and

$$
\omega\left(p\left(A_{i} x, A_{j} y\right)\right) \leq M_{i j}(x, y)
$$

for any $x, y \in X$ and distinct $i, j \in \mathbb{N}$.

Proof. It follows immediately from Lemma 3.1.

Remark 3.1. In Theorem 1.2, Cirić et al. assumed that the hypothesis $p(A x, B y) \leq \varphi$ $(M(x, y))$ is satisfied for all $x, y \in X$ with $\varphi \in \Phi$ and obtained a common fixed point result.

In particular from the assumptions on that $\varphi$, (JT2) holds for $A_{1}=A$ and $A_{2}=B$. So, by Theorem 3.2, (JT1) holds, that is; for all $\varepsilon>0$, there exists $\delta>0$ such that for all $x$, $y \in X$

$$
\varepsilon \leq M(x, y)<\varepsilon+\delta \Rightarrow p(A x, B y)<\varepsilon,
$$

By Lemma 3.1 of Jachymski [31], (20) implies (as in metric cases) that the conditions (C2) and (C3) are satisfied, but nothing on the condition (C4). Conversely, in Theorem 2.3 we have assumed that (C2) and (C3) hold, but we added another condition which is (C4) in order to get a common fixed point result.

Remark 3.2. Theorem 2.3 is the analogous of Theorem 1 of Rana et al. [32] on partial metrics, except that the conditions (20) and the fact that $a, b \in[0,1]$, are replaced by the weaker conditions (C2), (C3) and $a, b \in\left[0, \frac{1}{2}\right]$. The condition on $a$ and $b$ is modified due to the fact that $p(x, x)$ may not equal to 0 for $x \in X$. Also, Corollary 2.4 extends Theorem 2.1 of Bouhadjera and Djoudi [33]on partial metric cases. Note that Theorem 


\section{1 in [33]was improved recently by Akkouchi [[34], Corollary 4.4]. Indeed, the Lipschitz constant $k$ is allowed to take values in the interval $\left[0, \frac{1}{2}\right]$ instead of the case studied in [33], where the constant $k$ belongs to the smaller interval $\left[0, \frac{1}{3}\right]$.}

\section{Author details}

${ }^{1}$ Institut Supérieur d'Informatique et des Technologies de Communication de Hammam Sousse, Université de Sousse, Route GP1-4011, Hammam Sousse, Tunisie ²Department of Mathematics, Atılım University, İncek, Ankara 06836, Turkey

\section{Authors' contributions}

The authors have contributed in obtaining the new results presented in this article. All authors read and approve the final manuscript.

\section{Competing interests}

The authors declare that they have no competing interests.

Received: 28 November 2011 Accepted: 24 February 2012 Published: 24 February 2012

\section{References}

1. Matthews, SG: Partial Metric Topology. In: Susan J. Andima, Gerald Itzkowitz, T. Yung Kong (eds.) Papers on General Topology and Applications, Eighth Summer Conference at Queens College, Annals New York Acad Sci.183-197 (1994)

2. Kopperman, RD, Matthews, SG, Pajoohesh, H: What do partial metrics represent? In: Kopperman, R, Smyth, MB, Spreen, D, Webster, J (eds.) Spatial Representation: Discrete vs. Continuous Computational Models, Dagstuhl Seminar Proceedings.1-4 (2005)

3. Künzi, HPA, Pajoohesh, H, Schellekens, MP: Partial quasi-metrics. Theor Comput Sci. 365(3):237-246 (2006). doi:10.1016/j. tcs.2006.07.050

4. Romaguera, S, Schellekens, M: Duality and quasi-normability for complexity spaces. Appl General Topol. 3, 91-112 (2002)

5. Schellekens, MP: A characterization of partial metrizability: domains are quantifiable. Theor Comput Sci. 3, 91-112 (2002)

6. Abdeljawad, T, Karapınar, E, Tas, K: Existence and uniqueness of common fixed point on partial metric spaces. Appl Math Lett. 24(11):1900-1904 (2011). doi:10.1016/j.aml.2011.05.014

7. Altun, I, Erduran, A: Fixed point theorems for monotone mappings on partial metric spaces. Fixed Point Theory Appl 1-10 (2011). 2011, (Article ID 508730)

8. Altun, I, Sola, F, Simsek, H: Generalized contractions on partial metric spaces. Topol Appl. 157(18):2778-2785 (2010). doi:10.1016/j.topol.2010.08.017

9. Altun, I, Sadarangani, K: Corrigendum to generalized contractions on partial metric spaces. Topol Appl 157, 2778-2785 (2010). Topol. Appl. 158(13), 1738-1740 (2011), doi:10.1016/j.topol.2010.08.017

10. Aydi, H: Some fixed point results in ordered partial metric spaces. J Nonlinear Sci Appl. 4(3):210-217 (2011)

11. Aydi, H: Some coupled fixed point results on partial metric spaces. Int J Math Math Sci 1-11 (2011). 2011, (Article ID 647091)

12. Aydi, H: Fixed point results for weakly contractive mappings in ordered partial metric spaces. J Adv Math Studies. 4(2):1-12 (2011)

13. Aydi, $\mathrm{H}$ : Fixed point theorems for generalized weakly contractive condition in ordered partial metric spaces. J Nonlinear Anal Opt Theory Appl. 2(2):33-48 (2011)

14. Aydi, $\mathrm{H}$ : Common fixed point results for mappings satisfying $(\psi, \bigotimes)$-weak contractions in ordered partial metric spaces. Int J Math Stat. 12(2):53-64 (2012)

15. Aydi, $\mathrm{H}$ : A common fixed point result by altering distances involving a contractive condition of integral type in partial metric spaces. Demonstratio Math. (in press)

16. Aydi, H, Karapınar, E, Shatanawi, W: Coupled fixed point results for $(\psi, \varphi)$-weakly contractive condition in ordered partial metric spaces. Comput Math Appl. 62(12):4449-4460 (2011). doi:10.1016/j.camwa.2011.10.021

17. Ćirić, Lj, Samet, B, Aydi, H, Vetro, C: Common fixed points of generalized contractions on partial metric spaces and an application. Appl Math Comput. 218(6):2398-2406 (2011). doi:10.1016/j.amc.2011.07.005

18. Karapınar, E: Weak $\boldsymbol{\otimes}$-contraction on partial metric spaces. J Comput Anal Appl. 14(2):206-210 (2012)

19. Karapınar, E, Erhan, IM: Fixed point theorems for operators on partial metric spaces. Appl Math Lett. 24(11):1894-1899 (2011). doi:10.1016/j.aml.2011.05.013

20. Karapınar, E: Generalizations of Caristi Kirk's theorem on partial metric spaces. Fixed Point Theory Appl 4 (2011). 2011:

21. Karapınar, E, Yuksel, U: Some common fixed point theorems in partial metric spaces. J Appl Math 1-17 (2011). 2011, (Article ID 263621)

22. Chi, KP, Karapınar, E, Thanh, TD: A generalized contraction principle in partial metric spaces. Math Comput Model. 55(56):1673-1681 (2012). doi:10.1016/j.mcm.2011.11.005

23. Karapınar, E: A note on common fixed point theorems in partial metric spaces. Miskolc Math Notes. 12(2):185-191 (2011)

24. Oltra, S, Valero, O: Banach's fixed point theorem for partial metric spaces. Rend Istit Mat Univ Trieste. 36(1-2):17-26 (2004)

25. Romaguera, S: Fixed point theorems for generalized contractions on partial metric spaces. Topl Appl. 159, 164-199 (2012)

26. Samet, B, Rajović, M, Lazović, R, Stojiljković, R: Common fixed-point results for nonlinear contractions in ordered partial metric spaces. Fixed Point Theory Appl 71 (2011). 2011 
27. Shatanawi, W, Samet, B, Abbas, M: Coupled fixed point theorems for mixed monotone mappings in ordered partial metric spaces. Math Comput Model. 55(3-4):680-687 (2012). doi:10.1016/j.mcm.2011.08.042

28. Valero, O: On Banach fixed point theorems for partial metric spaces. Appl General Topol. 6(2):229-240 (2005)

29. Jungck, G: Compatible mappings and common fixed points. Int J Math Math Sci. 9, 771-779 (1986). doi:10.1155/ S0161171286000935

30. Jachymski, J: Equivalent conditions and the Meir-Keeler type theorems. J Math Anal Appl. 194, 293-303 (1995). doi:10.1006/jmaa.1995.1299

31. Jachymski, J: Common fixed point theorems for some families of maps. Ind J Pure Appl Math. 25(9):925-937 (1994)

32. Rana, R, Dimri, RC, Tomar, A: Some fixed point theorems on Meir-Keeler type under strict contractions. Int J Comput Appl. 17(3):24-30 (2011)

33. Bouhadjera, H, Djoudi, A: On common fixed point theorems of Meir and Keeler type. An Şt Univ Ovidius Constanta. 16(2):39-46 (2008)

34. Akkouchi, M: A Meir-Keeler type common fixed point theorem for four mappings. Opuscula Math. 31, 5-14 (2011)

doi:10.1186/1687-1812-2012-26

Cite this article as: Aydi and Karapinar: A Meir-Keeler common type fixed point theorem on partial metric spaces.

Fixed Point Theory and Applications 2012 2012:26.

\section{Submit your manuscript to a SpringerOpen ${ }^{\circ}$} journal and benefit from:

- Convenient online submission

- Rigorous peer review

- Immediate publication on acceptance

- Open access: articles freely available online

- High visibility within the field

- Retaining the copyright to your article

Submit your next manuscript at $\gg$ springeropen.com 